\title{
PLANEJAMENTO DE OBRA CIVIL: CONDICIONANTES DE PROJETO
}

\section{ARTIGO DE REVISÃo}

SOUZA, Faine Segura De ${ }^{1}$

HENRIQUE, Rosana Maria ${ }^{2}$

SOUZA, Faine Segura De. HENRIQUE, Rosana Maria. Planejamento de obra civil: Condicionantes de projeto. Revista Científica Multidisciplinar Núcleo do Conhecimento. Ano 05, Ed. 06, Vol. 05, pp. 154-166. Junho de 2020. ISSN: 24480959, Link de acesso: https://www.nucleodoconhecimento.com.br/arquitetura/condicionantes-deprojeto

\section{RESUMO}

O planejamento de uma obra civil diz respeito a implantação ordenada de empreendimentos em edificações e, nessa área de atuação, as condicionantes de projeto são os fatores que determinam os objetivos e uso do que será realizado. $O$ presente trabalho apresenta um planejamento orientado pelas normas e leis, seguido da definição do que é um projeto, seu ciclo de vida resumido e a necessidade de evitar erros comuns, a fim de alcançar os objetivos de um produto final visualmente agradável, que não prejudique sua funcionalidade e possibilite alterações para acompanhar as inovações tecnológicas. Para fortalecer a ideia de evitar erros é apresentado o efeito do risco das mudanças em relação aos custos das mesmas. Por fim, são ofertadas as principais condicionantes de projeto e como interferem na

\footnotetext{
${ }^{1}$ Arquiteta. Pós graduando: Especialização em planejamento e controle de obras.

2 Bióloga. Doutorado em Ciências. Mestrado em Ecologia. Especialização em Gestão e Práticas Ambientais. Aperfeiçoamento em Gestão socioambiental aplicada à energia hidreletr. Aperfeiçoamento em Individual Training in Industrial Waste Treatment.
} 
viabilização do mesmo. Este trabalho foi desenvolvido com base nos conhecimentos adquiridos no âmbito acadêmico e em pesquisa bibliográfica.

Palavras-chave: Planejamento de Obras, projeto civil, condicionantes de projeto, ciclo de vida.

\section{INTRODUÇÃO}

As edificações de sucesso seguem um planejamento que busca atender as necessidades presentes dos usuários e as tendências de futuro. O presente estudo tem a premissa de direcionar o olhar crítico dos responsáveis por obras civis em busca de alcançar a efetividade no planejamento e controle de obras. Observadas as não conformidades mais recorrentes em edificações, foram lançadas as seguintes conjecturas: De que forma prédios e espaços comuns poderiam ser mais bem planejados, com vistas a prevenir erros de implantação? E quais adequações poderiam ser realizadas em edifícios para evitar danos à arte e prejuízos ao espaço?

De forma adicional, o presente estudo fornece subsídios demonstrando que, a espelho de um maestro, o pensamento do gestor de obras deve progredir de um modelo linear para multidisciplinar, tornando-o capaz de prever, adequadamente, as variáveis tangíveis e intangíveis que possam intervir nas diversas etapas de um projeto. Para tanto, há necessidade de o gestor qualificar-se em modelos de planejamento, notadamente, aqueles voltados à gestão de equipes e projetos, e sistemas de monitoramento preventivos para garantir o conforto e a segurança dos colaboradores.

O tema é amplo, motivo pelo qual, não se tem como premissa esgotar as conjecturas possíveis, mas sim, fornecer subsídios às boas práticas de planejamento de obras valendo-se, sobretudo, do amplo acesso a informação e canais de disseminação de conhecimentos, normas, leis e tendências, atualmente disponíveis.

Questão Problema: De que maneira o emprego de tecnologias e conhecimentos pode evitar a ocorrência de não conformidades comumente observadas em edificações? 
Problema: A constante necessidade de reformar novas edificações com o objetivo de corrigir vícios/imperfeições estruturais; e/ou implantar medidas para adequá-las aos critérios normativos ou ao uso a princípio destinado.

Parte deste problema deve-se a erros cometidos em todas as etapas, seja por negligência ou por falta de fiscalização e/ou orientação técnica.

Objetivo Geral: Apontar as principais condicionantes que devem ser observadas para realização de um bom projeto de construção civil.

Objetivos Específicos: Levantar os pontos principais que devem ser considerados ao se planejar uma obra; direcionar os caminhos para a realização de um projeto de edificação e indicar ferramentas de apoio ao processo de planejamento e controle de obras civis.

Justificativa: existe a necessidade de um olhar mais criterioso na construção civil, pois é inconcebível que haja tantos erros, dado que nossa sociedade moderna apresenta uma variedade de tecnologias para suporte nas áreas de engenharia, economia e indústria, permeadas com o avanço da informática numa Quarta Revolução Industrial[3] e uma cultura de nativos digitais[4].

As cidades crescem com velocidade espantosa e precisam de uma acuidade a fim de fornecer serviços de boa qualidade que possam garantir as necessidades das pessoas e para isso existe a necessidade de bons projetos, do início ao fim, pensando a frente das necessidades presentes.

Frente às demandas atuais de desenvolvimento sustentável é imprescindível um trabalho em projetar dentro das conjecturas atuais. O governo tem amplamente divulgado os Objetivos de Desenvolvimento Sustentável (ODS)[5] que ambicionam um uso sustentável dos recursos e os teóricos, seguindo as tendências, postulam essa necessidade e as justificam como nas palavras de Douglas Farr (2013), que aponta o urbanismo sustentável como aspecto importante da mudança de postura das novas gerações em seus projetos e empreendimentos e a sua adoção como norma 
social a ser praticada por todos os envolvidos no processo de planejamento urbano em uníssona harmonia para atingir um propósito compartilhado.

Entendendo que se tomado algumas medidas e um estudo direcionado é possível realizar um planejamento que atenda as necessidade e exigências de qualidade e sustentabilidade.

Para este estudo teórico foi utilizado o método de pesquisa em meios físicos e eletrônicos como livros e sites.

\section{REFERENCIAL TEÓRICO}

A falta de planejamento é um dos motivos existentes para os consecutivos erros. A visão de gerenciamento de projetos segue parâmetros que definem a qualidade do empreendimento, da concepção, passando pela execução até conclusão, respeitando os trâmites legais. O primeiro pensamento que deve perturbar um projetista é de evitar problemas em seus empreendimentos são os contratos, leis e licenciamentos. Os contratos com os clientes, colaboradores, de loteamento ou divisões de terreno podem conter cláusulas até mais rígidas que as próprias leis governamentais.

Leis, normas e orientações devem ser cumpridas, se não, podem gerar multas e até embargos de obras. Podemos citar o Código de Obras e Edificações (COE), em São Paulo foi aprovado pela Lei $\mathrm{n}^{\circ}$ 16.642, de 9 de maio de 2017 e regulamentado pelo Decreto $n^{\circ} \mathbf{5 7 . 7 7 6}$, de 7 de julho de 2017 , de procedimentos relativos a construção civil.

Este decreto regulamenta os procedimentos administrativos e executivos e fixa as regras gerais e específicas a serem obedecidas no projeto, licenciamento, execução, manutenção, utilização e fiscalização de obras, edificações, equipamentos, obras complementares, terraços e mobiliários, dentro dos limites dos imóveis em que se situam (PMSP, DECRETO № 57.776, Art. 1ํ). 
Acatados os regulamentos, o proprietário ou seu representante solicitará para as autoridades competentes os documentos de controle de atividades edilícia (garantem a regularização do imóvel), que são os licenciamentos, como os alvarás: de demolição, de aprovação, de execução; os certificado de conclusão, habite-se entre outros.

Recomendações de normas técnicas NRs devem ser acatadas quando previstas para aprovações ao atenderem requisitos de segurança, proteção, conforto, saúde, incluindo diretrizes de ordem administrativa, organização e de planejamento nestes requisitos.

Para dar suporte nos procedimentos existem as NBRs, com normas e orientações de como fazer, mas não obrigatórias, no entanto se atendidas valorizam o empreendimento e fortalece que o empreendimento um planejamento, podendo receber certificações valorizadas no mercado.

O uso das NRs e NBRs traz diversos benefícios para o projeto como qualidade, produtividade, redução de custos, competitividade no mercado, aproveitamento de recursos e a garantia de um ótimo produto final.

Livros, manuais e guias também contém ótimos materiais orientativos para um planejamento eficiente, mutos deles sendo referência no quesito de Gestão de Projetos que expõem modelos e técnicas de planejamento e controle de obras civis, como Diagrama de Gantt[6], Método do Caminho Crítico e Técnica de Avaliação e Revisão b (PERT/CPM)[7], Linhas de Balanço[8], Location-based Management System (LBMS)[9] e Modelagem 4D - BIM[10] (MAGALHÃES, 2018).

\subsection{PROJETO}

Projeto é um empreendimento planejado, orientado à resultados, possuindo atividades com início e término, para atingir um objetivo claro e definido (BRASIL, 2011). Há vários motivos para o surgimento de um projeto que basicamente visa atender a necessidade da sociedade, de um grupo ou individual, atender uma necessidade 
reorganizacional, de alterações por conta do avanço tecnológico, atender a requisitos legais e atender ou corrigir os impactos ambientais. Tendo seu início com a análise da viabilidade a priori da solicitação do proprietário ou para atender uma demanda e a seguir elaborar um termo de abertura do projeto para documentar e oficializar o empreendimento onde se deve conter os objetivos e o cenário pretendido após a implantação do projeto, definir o escopo, prazos, custos, premissas e restrições, identificar riscos, definir equipe e infraestrutura, identificar os interessados e coletar aprovação e definir uma data para o início do projeto.

Num projeto se leva em conta as soluções para o problema principal e para os secundários relativos as necessidades dos usuários e da vizinhança, para as restrições encontradas, com fundamentos técnicos conhecidos e uma linguagem com representações que possam ser entendidos por todos.

O ciclo de vida é composto pelas especificidades do projeto e podem ser influenciado pelos aspectos exclusivos da organização, do setor, do método, de desenvolvimento ou da tecnologia utilizada. Mas basicamente estruturado como: Início de projeto; Organização e preparação (Planejamento); Execução do trabalho; encerramento do projeto, conforme PMBOK (2017). Brasil (2011), traça um organograma simplificado semelhante, conforme figura 1.

Figura 1 - Ciclo de vida de um projeto.

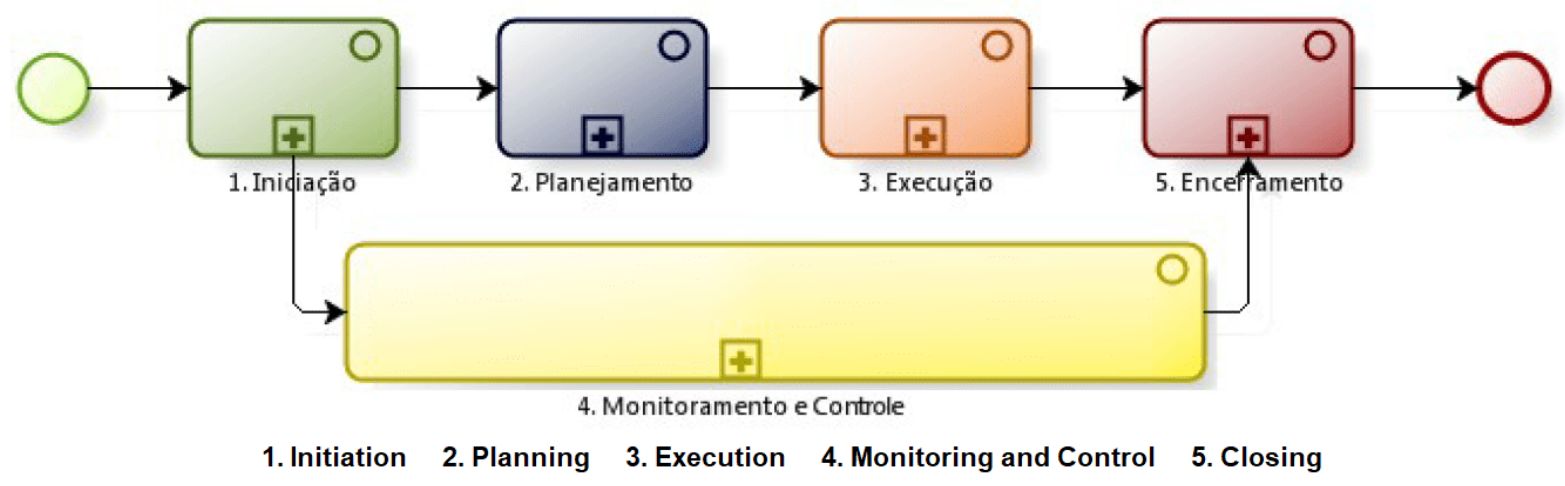

Fonte: Brasil, 2011. 
O planejamento e composto de processos realizados para planejar as ações do projeto a fim de alcançar os objetivos para os quais o projeto foi criado (BRASIL, 2011, p. 29), durante estes processos há o Monitoramento e Controle que:

São os processos realizados para observar a execução do projeto, de forma que possíveis problemas possam ser identificados no momento adequado e que possam ser tomadas ações preventivas e corretivas, quando necessário, para controlar a execução do projeto. O principal benefício deste grupo de processos é que o desempenho do projeto é observado e medido regularmente para identificar variações em relação ao plano de gerenciamento do projeto.(BRASIL, 2011, p. 29)

Se bem planejado um projeto tem grandes chances de sucesso e não é bom contar com a sorte. $O$ registro ajuda a identificar onde definir regras ou diretrizes para alinhar as ações da equipe e um relatório da qualidade (PMBOK, 2017).

Os processos de planejamento envolve definir o escopo que compreende elaborar um cronograma, plano de custos, definir qualidade, equipe, planejar a comunicação, identificar e analisar riscos, planejar as aquisições e contratações, convergindo para consolidar um plano de gerenciamento de projeto.

Todo este trabalho é realizado para eliminar ou minimizar os riscos por conta de alterações de projeto, descumprimento de normas ou erros.

Para manter um controle é importante avaliar os riscos de cada possibilidade do projeto, alterar o projeto para uma solução a fim de evitar os riscos ou inserir no projeto uma estrutura que possa eliminar o risco. O registro de riscos fornece informações sobre ameaças e oportunidades que ocorrerem durante a execução do projeto, manter um relatório de riscos fornece informações sobre os riscos gerais do projeto, além de informações resumidas sobre riscos individuais especificados (PMBOK, 2017).

O planejamento de projeto deve oportunizar para as partes interessadas a fala com possível influência nas características finais da edificação, para que as mudanças de projeto não sejam significativas no momento da execução a fim de evitar o aumento 
significativo dos custos e do cronograma. Segundo a Figura 2, essas mudanças são bem vindas ao início do projeto por serem de baixo custo e indesejadas na execução onde os custos aumentam progredindo para o seu término.

Figura 2 - Impacto de variáveis ao longo do projeto.

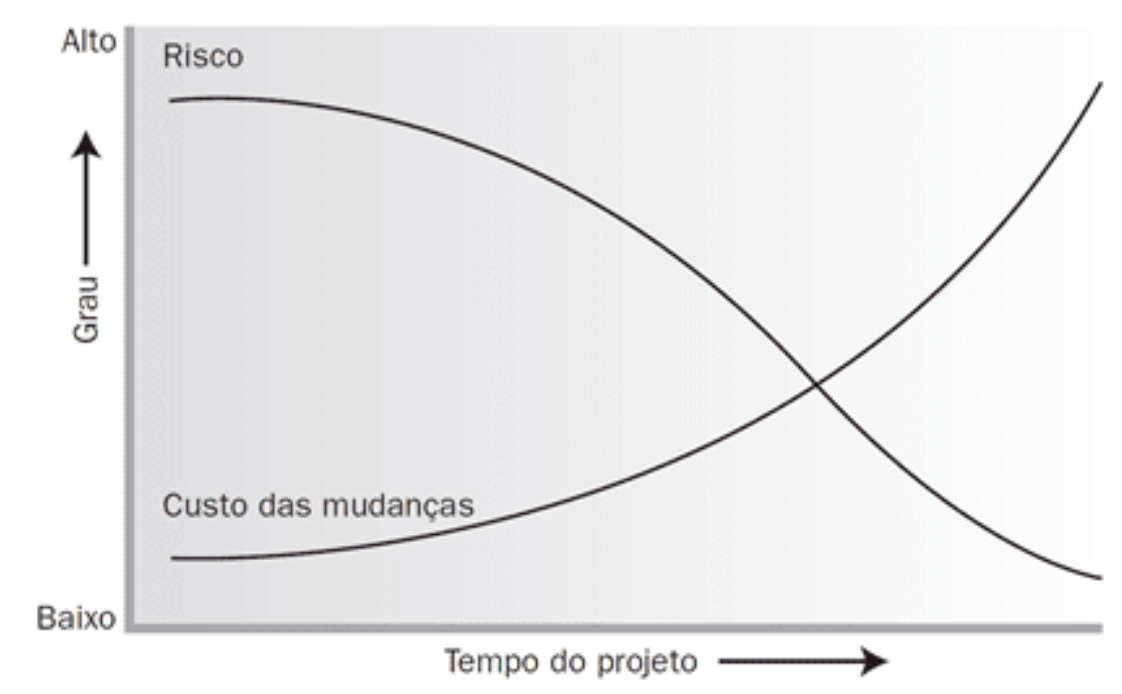

Alto=Higth; Risco=Risk; Grau=degree; Custo das mudanças=Cost ofchanges; Baixo=Low; Tempo de projeto=project time

Fonte: PMBOK, 2017(tradução própria).

Lições aprendidas são usadas para melhorar o desempenho do projeto e evitar a repetição de erros que podem acontecer ao longo do ciclo de vida. É importante registrar os problemas e soluções, pois a partir disso definir regras de ações. Manter a fiscalização da qualidade desde a organização do canteiro de obra, materiais recebidos, das equipes, até as conclusões, registrando as melhorias, as ações corretivas, mantendo, assim, um controle de qualidade.

O controle de qualidade é importante para se evitar erros.

Cumprir os requisitos do cliente sobrecarregando a equipe do projeto pode resultar em redução dos lucros e aumento dos níveis de riscos gerais do projeto, atritos entre os funcionários, erros ou 
retrabalho. Cumprir os objetivos do cronograma do projeto apressando as inspeções de qualidade planejadas pode resultar em erros não detectados, redução de lucros e aumento de riscos pós-implementação (PMBOK, 2017, p. 274).

Zela-se por um planejamento baseado nas condicionantes que podem interferir na decisão do escopo e seus objetivos. Por isso, se considera que é preferível gastar tempo com um bom planejamento entre as equipes, revendo os planos das diversas áreas que compõem o projeto para prevenir erros, visando a qualidade nas entregas do que após uma inspeção ou após o uso ser encontrado problemas. Inspeções são importantes para manter o erro fora do alcance do cliente, mas é preferível que seja isento.

Aparecendo a necessidade de alterações no escopo do projeto é importante que haja condições plausíveis para isto, ou seja, identificar o caráter da mudança, a fim de minimizar retrabalhos, extensão dos prazos, atrasos e visando a motivação da equipe, lembrando que uma alteração pode ter efeito na estrutura, hidráulica, paisagismo, elétrica e outras.

Para todos os fatores que influenciam no projeto e sua qualidade, existem limitantes ou direcionamento condicionados ao sistema de informações de gerenciamento de projetos, ao software de gerenciamento da qualidade usado para identificar erros e variações nas etapas, regulamentações de órgãos governamentais e normas, padrões e diretrizes específicos da área de aplicação.

\subsection{CONDICIONANTES DE BASE DE UM PROJETO}

Douglas Farr (2013), faz um estudo baseado no estilo de vida do norte americano e cita que "a escolha mais fundamental que os norte-americanos fazem é onde morar; esta decisão determina muita das consequências imprevistas de nosso estilo de vida", esta frase serve para qualquer ser humano em qualquer parte do planeta, pois afeta na saúde e felicidade. Onde morar é um luxo que nem todos podem determinar com precisão, mas pode optar como será essa moradia: apartamento, casa térrea ou 
sobrado; num terreno que terá suas características e propiciará determinadas escolhas de projeto.

Para Ching (2017), os fatores do clima, a topografia e o habitat influenciam as decisões do projeto e se for “... responsivo e sustentável respeita os atributos naturais de um lugar, adapta a forma e o layout de uma edificação à paisagem e leva em consideração o percurso do sol, a velocidade do vento e o fluxo da água..." para acomodar as pessoas com conforto, economizar energia e recursos materiais.

O planejamento de uma obra na construção civil é algo que precede a execução, sendo assim, é algo previsível, pois existem procedimentos até sua aprovação que coletam informações, das condições da natureza e serviços no local, para decisões das especificações de um projeto. $O$ planejamento acontece para o bom andamento dos trabalhos de locação, aquisição de materiais, logística, e segue durante as operações de execução, por isso deve levar em conta os fatores imprevisíveis de produção, de mão de obra, prazos, e coordenação de múltiplas atividades.

Não existe receita fixa de se fazer uma edificação, existem muitas maneiras e com a criatividade e critérios é possível ampliar a escolha de como melhorar o que se está construindo (LENGEN, 2014). Para condicionantes de base foi considerado os fatores que influenciam na concepção do projeto a fim de reconhecê-la como boa e do que é composta. E pra isto é preciso entender que uma boa abra responde as condicionantes do projeto.

O clima influência na escolha do designer, restringe o uso certos tipos de materiais e oferece oportunidade de superação e fim de inovar ou de manter o tradicional. Segundo Lengen (2014), a casa serve para proteger as pessoas e acomodar os bens das condições climáticas, como calor, chuva, frio ou umidade, e por isso é importante observar primeiro o clima local.

Segundo Lengen (2014), topografia, ou seja, a forma do terreno ou da vegetação faz com que os espaços mudem, dependendo do relevo pode compor espaços em 
diferentes níveis unidos por escadas ou rampas, mantendo no mesmo nível espaços que tem relação entre si.

A análise do terreno ou sítio e seu entorno é o processo de estudo das forças contextuais que influenciam a maneira na qual iremos implantar uma edificação e orientar seus espaços, configurar e articular suas vedações externas e estabelecer suas relações com a paisagem. Todas as análises de terreno começam com a coleta de dados físicos do local. (CHING, 2017, p. 6)

Claro que muitas vezes se procura aproveitar ao máximo o terreno, plainando e fazendo muros de arrimo, de contenção e impermeabilização, gastando se mais na fundação e por fim não tendo um ambiente agradável nos ambiente que ficam abaixo do nível do solo. Mas o melhor é que a planta siga a forma o terreno (LENGEN, 2014), portanto a ocupação e construção do terreno deve minimizar a interferência nos padrões de drenagem (CHING, 2017), pois um dos maiores inimigos da edificação é a água.

Um estudo do solo é necessário para análise do que pode ser construído sobre este, buscando identificar o tipo de solo por meio de sondagem e suas características de capacidade de carregamento admissível, densidade, resistência ao cisalhamento, altura do lençol freático (CHING, 2017).

A orientação, ou seja, a posição da edificação em relação ao caminho que o sol faz entre o nascer e ao se por, influencia na iluminação natural por meio da insolação. O relevo e a vegetação, a localização influenciam na entrada de ar pelos ventos, bem como a forma da edificação e a posição de muros e portas e janelas escolhidas.

A posição dos espaços no local deve tender a facilitar o fluxo de pessoas e veículos, os compartimentos de permanência transitória não necessitam de estudos acurados em sua orientação, podendo mesmo ser orientados até para o quadrante Norte e o Oeste, que são de fato os 
mais inconvenientes no que diz respeito à insolação das fachadas e interiores para nossa latitude de 2352' (PAIXÃO, 2014, p.18).

Os forros e telhados tendem a facilitar o fluxo de ar, da ventilação e do escoamento das águas das chuvas.

O que é relevante em qualquer discussão sobre projeto sustentável é que a maior parte do consumo de energia da indústria da edificação não é atribuída à produção de materiais ou ao processo de construção, e sim aos processos operacionais - calefação, refrigeração e iluminação de edificações. Isso significa que, para reduzir o consumo de energia e as emissões de gases com efeito estufa geradas pelo uso e manutenção de edificações ao longo de sua vida útil, é necessário projetar, implantar e configurar edificações adequadamente, bem como incorporar aquecimento, refrigeração, ventilação e estratégias de iluminação naturais (CHING, 2017, p. 5).

Para completar ou melhorar a iluminação e arrefecimento dos ambientes é esperado que se faça a escolha adequada da calefação solar passiva que se refere ao uso de energia solar para aquecer os espaços internos de uma edificação sem precisar de equipamentos mecânicos que exijam energia adicional, segundo Ching (2017) e postula que há dois elementos essenciais em todo sistema solar passivo: o vidro ou plástico transparente orientado para o norte para a captura de radiação solar (no hemisfério sul) e uma massa termo acumuladora para a coleta, armazenagem e distribuição de calor, orientada para receber o máximo de exposição solar que são as alvenarias em geral, esses atributos tem o objetivo de irradiar saúde a casa e ao seus ocupantes. Como um componente essencial de sustentabilidade, as edificações sustentáveis buscam oferecer ambientes saudáveis de uma maneira eficiente, usando princípios fundamentados ecologicamente (CHING, 2017).

O planos diretor é um termo municipal que regula e define o uso e a ocupação do solo para controlar os padrões fundiários, controlar a densidade de construção, direcionar 
o desenvolvimento para áreas com infraestrutura e amenidades adequadas, proteger áreas ambientalmente sensíveis e conservar a espaço aberto. (CHING, 2017)

Em qualquer lugar, rural ou urbano, haverá uma norma de ocupação que regulamentará os tipos de atividades, o volume da edificação, os recuos e outros itens, por isso é necessário consultar as normas municipais.

Os espaços dependem muito do tipo de uso, se for residencial deve atender as necessidades específicas dos seus futuros moradores, se for coletivo deve atender os costumes e cultura, mas em ambos os casos é importante pensar nas áreas verdes, iluminação natural, arejamento, acessibilidade e segurança, pensando no uso de cada um e dos móveis que entrarão neles. Uma boa disposição de espaços pode economizar área. (LENGEN, 2014)

Considerando as pesquisas realizadas, pode-se dizer que existem informações suficientes para planejar e controlar um projeto ao alcance de todos, basta um pouco acuidade e bom senso para que se atenda as condicionantes para um bom projeto $e$ resultados satisfatórios.

Com uma gama de materiais existentes amplia a criatividade, artes podem ser mais delgadas ou apresentarem curvas incríveis. Os materiais podem definir os prazos, o uso de materiais pré-fabricados podem acelerar o processo, mas podem ser de maior custo. Existe uma diversidade de materiais, técnicas e tecnologias que se renovam a cada dia, muitas acessíveis; e uma difusão de conhecimento em sites especializados o que possibilita diversas soluções inovadoras para a arquitetura e engenharia. Diante disso é papel do arquiteto filtrar as possibilidades diante das condicionantes de projeto, ajustar o sonho dos interessados à realidade e adotar as melhores soluções para cada caso. A criatividade é um reflexo da vivência da pessoa que cria o projeto e no caso de uma construção ter a participação de todos os envolvidos é importante para troca de ideias, entre os colaboradores e o cliente, em mútua confiança, pois saber identificar as necessidades do cliente é tão importante quanto ouvir os parceiros da obra. Dentro das perspectivas do projeto pode ser adotado um modelo, estilo ou tendências para compor a arte final e não pode ficara de fora a ideia de 
sustentabilidade que é um assunto que está em todas as esferas, num esforço global para minimizar o impacto ambiental negativo do desenvolvimento por meio da eficiência e o uso consciente dos materiais, energia e recursos.

Este trabalho não esgota o tema e pode contribuir para que um leitor e projetista saiba que é importante ouvir o cliente com atenção, o que engloba todo o grupo que vai ser usuário dos espaços, permitir um processo de conhecer o cliente, seus propósitos, sua visão, sua missão e estar aberto à contribuição dos colaboradores; ver e ouvir a natureza local e suas possibilidades, atendendo os requisitos de topografia, clima e orientação, assim é possível aproveitar bem os recursos naturais e atender o requisito de sustentabilidade.

\section{CONSIDERAÇÕES FINAIS}

Um bom projeto é aquele planejado observando as condicionantes de projeto resolvendo a maior parte dos problemas existentes, considerando o terreno e seu entorno, respeitando normas e leis, buscando outras soluções quando necessárias, prevendo e criando soluções para os principais problemas criados pela existência do empreendimento, a funcionalidade, tecnicamente bem estabelecido e eficiente em todas as suas estruturas e detalhes, bem como harmonicamente elaborado artisticamente.

As condicionantes não devem ser obstáculos e nem motivo para padronizar gostos e vontades, pois tudo deve contribuir para ampliar o diálogo entre o cliente e o profissional e encontrar soluções mais adequadas para um determinado contexto.

\section{REFERÊNCIAS}

BRASIL. Metodologia de gerenciamento de projetos do SISP. Brasília: Ministério do Planejamento, Orçamento e Gestão, 2011.

CHING, Francis D.K.. Técnicas de construção ilustradas, 5. ed. São Paulo: 2017. 
FARR, Douglas. Urbanismo sustentável: desenho urbano com a natureza. Porto Alegre: Bookman, 2013.

LENGEN, John Van. Manual do arquiteto descalço. São Paulo: B4 Editora, 2014.

MAGALHÃES, RM; MELLO, LCBB; BANDEIRA, RAM. Planejamento e controle de obras civis: estudo de caso múltiplo em construtoras no Rio de Janeiro. Transinfo [Internet]. 2018 [acesso em 29 nov. 2019]; 25(1): 44-55. Disponível em: http://www.scielo.br/scielo.php?script=sciartt ext\&pid=S0104530X2018000100044\&lng=pt\&tlng=pt

PAIXÃO, Luciana. Um Guia do Conhecimento em Gerenciamento de Projetos (Guia PMBOK). 6를 ed. Pennsylvania: Project Management Institute Inc., 2017.

PROJECT MANAGEMENT INSTITUTE. Um Guia do Conhecimento em Gerenciamento de Projetos (Guia PMBOK). 6ª ed. Pennsylvania: Project Management Institute Inc., 2017.

SÃO PAULO. Gestão Urbana da PMSP. Decreto ㄲo 57.776, de 7 de julho de 2017. Regulamenta a Lei oㅜ 16.642, de 9 de maio de 2017, que aprovou o Código de Obras e Edificações do Município de São Paulo; define os membros da Comissão de Edificações e Uso do Solo - CEUSO. Diário Oficial da Cidade de São Paulo. 2017 jul. 8; Seção Leis. p 1.

\section{APÊNDICE - REFERÊNCIAS DE NOTA DE RODAPÉ}

3. Sistemas conceituados nos impactos causados pelo avanço da tecnologia da informática. Ficou conhecido na Alemanha pelo termo de Indústria 4.0 e seu propósito é de integrar o homem, a tecnologia e a informação, através das fábricas inteligentes.

4. Nascidos na era digital, isto é, depois de 1980, as quais têm acesso às tecnologias digitais da rede e possuem habilidades e conhecimentos de computação, fazendo parte de uma cultura global comum. 
5. 3. São 17 objetivos da Agenda 2030 que é um plano de ação para as pessoas, para o planeta e para a prosperidade. Ela também busca fortalecer a paz universal com mais liberdade. Reconhecemos que a erradicação da pobreza em todas as suas formas e dimensões, incluindo a pobreza extrema, é o maior desafio global e um requisito indispensável para o desenvolvimento sustentável. Proposto pela ONU em 2015. (https://nacoesunidas.org/pos2015/agenda2030/)

6. Desenvolvido por Henry L. Gantt em 1917, de representação gráfica das atividades em uma escala de tempo.

7. União do cronograma de rede, representados por setas pelo método do caminho crítico, possuindo um caráter determinístico, desenvolvido em 1957 pela E.I. Dupont de Neymours com o cronograma de rede de técnica de avaliação e revisão de programas de caráter probabilístico, em 1957 pelo Departamento de Defesa dos EUA.

8. Técnica de gráfico num plano cartesiano com linhas que representam uma atividade em seu respectivo tempo, sendo no eixo $x$ o tempo e no eixo y os valores acumulados.

9. Resulta da pesquisa da técnica de linha de balanço e do método Flowline e aperfeiçoa o fluxo de trabalho, evitando a ociosidade dos trabalhadores.

10. Conceito de integração e modelagem das informações de um projeto num modelo virtual 3D do edifício.

Enviado: Dezembro, 2019.

Aprovado: Junho, 2020. 